\title{
A New Framework for Adptive Sampling and Analysis During Long-Term Monitoring and Remedial Action Management
}

\author{
Minsker, Barbara \\ University of Illinois
}

RESULTS TO DATE: Yonas Demissie, a research assistant supported by the project, has successfully created artificial data and assimilated it into coupled Modflow and artificial neural network models. His initial findings show that the neural networks help correct errors in the Modflow models. Abhishek Singh has used test cases from the literature to show that performing model calibration with an interactive genetic algorithm results in significantly improved parameter values. Meghna Babbar, the third research assistant supported by the project, has found similar results when applying an interactive genetic algorithms to long-term monitoring design. She has also developed new types of interactive genetic algorithms that significantly improve performance. Gayathri Gopalakrishnan, the last research assistant who is partially supported by the project, has shown that sampling branches of phytoremediation trees is an accurate approach to estimating soil and groundwater contaminations in areas surrounding the trees at the Argonne $317 / 319$ site.

DELIVERABLES: Li, Xiaodong, and Barbara Bailey, "Hierarchical Bayesian space-time models for groundwater data", presented at American Statistical Association Joint Meetings, Toronto, Canada, 2004.

Michael, W. J., B. S. Minsker, D. Tcheng, and A. J. Valocchi, "Integrating Data Sources to Improve Hydraulic Head Predictions: A Hierarchical Machine Learning Approach." Water Resources Research, 41(3), 2005, W03020 10.1029/2003WR002802.

Minsker, B. S., P. Groves, and D. Beckmann "Optimizing Long Term Monitoring at a BP Site Using MultiObjective Optimization", American Society of Civil Engineers (ASCE) Environmental \& Water Resources Institute (EWRI) World Water \& Environmental Resources Congress 2005 \& Related Symposia, Anchorage, AK, 2005.

Singh, A., B. S. Minsker, and H. Takagi, "Interactive Genetic Algorithms for Inverse Groundwater Modeling", American Society of Civil Engineers (ASCE) Environmental \& Water Resources Institute (EWRI) World Water \& Environmental Resources Congress 2005 \& Related Symposia, Anchorage, AK, 2005. 